\title{
Processing of first- and second-order motion signals by neurons in area MT of the macaque monkey
}

\author{
LAWRENCE P. O'KEEFE AND J. ANTHONY MOVSHON \\ Howard Hughes Medical Institute and Center for Neural Science, New York University, New York \\ (Received May 1, 1997; Accepted September 23, 1997)
}

\begin{abstract}
Extrastriate cortical area MT is thought to process behaviorally important visual motion signals. Psychophysical studies suggest that visual motion signals may be analyzed by multiple mechanisms, a "first-order" one based on luminance, and a "second-order" one based upon higher level cues (e.g. contrast, flicker). Second-order motion is visible to human observers, but should be invisible to first-order motion sensors. To learn if area MT is involved in the analysis of second-order motion, we measured responses to first- and second-order gratings of single neurons in area MT (and in one experiment, in area V1) in anesthetized, paralyzed macaque monkeys. For each neuron, we measured directional and spatio-temporal tuning with conventional first-order gratings and with second-order gratings created by spatial modulation of the flicker rate of a random texture. A minority of MT and V1 neurons exhibited significant selectivity for direction or orientation of second-order gratings. In nearly all cells, response to second-order motion was weaker than response to first-order motion. MT cells with significant selectivity for second-order motion tended to be more responsive and more sensitive to luminance contrast, but were in other respects similar to the remaining MT neurons; they did not appear to represent a distinct subpopulation. For those cells selective for second-order motion, we found a correlation between the preferred directions of first- and second-order motion, and weak correlations in preferred spatial frequency. These cells preferred lower temporal frequencies for second-order motion than for first-order motion. A small proportion of MT cells seemed to remain selective and responsive for second-order motion. None of our small sample of V1 cells did. Cells in this small population, but not others, may perform "form-cue invariant" motion processing (Albright, 1992).
\end{abstract}

Keywords: Motion, Physiology, Extrastriate cortex, Macaque, Area MT

\section{Introduction}

Visual motion information may be processed by multiple independent mechanisms (Chubb \& Sperling, 1988, 1989; Cavanagh \& Mather, 1989; Sperling, 1989). The mechanism that has been most studied responds to "first-order" motion cued by the spatial distribution of luminance. An additional mechanism is thought to respond to "second-order" motion that is cued not by luminance, but by some other feature such as contrast, or spatial or temporal structure (Cavanagh \& Mather, 1989). The characteristics of the first-order mechanism are reasonably well accounted for by models in which selectivity is defined by the properties of linear spatiotemporal filters, usually followed by nonlinear processing elements (Watson \& Ahumada, 1983, 1985; Van Santen \& Sperling, 1984, 1985; Adelson \& Bergen, 1985).

First-order models can account for a variety of perceptual phenomena, including sampled (apparent) motion, reversed apparent motion, and missing-fundamental motion (Van Santen \& Sperling, 1984; Adelson \& Bergen, 1985). Recent psychophysical data sug-

Reprint requests to: Lawrence P. O'Keefe, Center for Neural Science, New York University, 4 Washington Place, Room 809, New York, NY 10003-6621, USA. gest that motion detection on static backgrounds (Lu \& Sperling, 1995) and motion segregation (Qian et al., 1994) are based on first-order computations. The components of reasonably implemented first-order models fit well with the properties of neurons in early stages of the visual cortex. Some simple cells have receptive fields that resemble the subunits often postulated by these models (Movshon et al., 1978; Reid et al., 1987; McLean \& Palmer, 1989; DeAngelis et al., 1993a,b; McLean et al., 1994). The responses of direction-selective complex cells in the primary visual cortex and of cells in extrastriate area MT are consistent with later stages of these models (Emerson et al., 1992; Britten et al., 1993; DeAngelis et al., 1993a,b; Qian \& Andersen, 1994; Simoncelli et al., 1996). Thus first-order motion sensing may involve a roughly linear spatiotemporal filtering of the retinal image, followed by a nonlinear combination of these linearly filtered signals to produce signals related to motion energy (Adelson \& Bergen, 1985).

For the "microbalanced" random stimuli developed by Chubb and Sperling (1988, 1989), the linear components of motion are balanced, and thus produce no net output from first-order mechanisms, yet the stimuli elicit a clear sensation of motion. This has led some to suggest an independent mechanism for the analysis of second-order motion (Chubb \& Sperling, 1988, 1989). On the other hand, Victor and Conte (1992) have suggested that a single 
mechanism might process both first- and second-order motion. Other schemes have been proposed in which motion signals from first- and second-order pathways are combined at the stage yielding a motion percept (Wilson et al., 1992; Wilson \& Kim, 1994; Zanker \& Hupgens, 1994). Psychophysical data thus do not provide a consensus view on where, or even how, second-order motion detection is done.

\section{Neural substrate for second-order motion?}

It is now well known that MT and neighboring areas in the superior temporal sulcus (see Maunsell \& Newsome, 1987, for a review) are intimately involved in the processing of first-order motion. Area MT receives direct input from direction-selective V1 neurons (Movshon \& Newsome, 1996), and in contrast to V1 and to other extrastriate visual areas, almost all MT neurons are selective for the direction of visual motion (Van Essen \& Maunsell, 1983; Felleman \& Kaas, 1984; Van Essen, 1985; Maunsell \& Newsome, 1987; Felleman \& Van Essen, 1991). There is compelling evidence that signals carried by neurons in area MT and its neighbor MST are critical to the perception of motion. Small excitotoxic lesions of area MT substantially (though transiently) elevate motion detection thresholds (Newsome \& Pare, 1988). The motion sensitivity of MT neurons is more than adequate to explain the sensitivity of behaving monkeys (Newsome et al., 1989; Britten et al., 1992), and there is a statistical association between MT neuronal responses to identical stimulus presentations and the behavioral choices made by the monkeys (Britten et al., 1996). Simulations of these results suggest an account of how neuronal signals in MT can be pooled to provide the signals supporting motion judgments (Shadlen et al., 1996). Furthermore, modifying the activity of MT neurons (by microstimulation) modifies perceptual judgment in the expected way (Salzman et al., 1990, 1992; Salzman \& Newsome, 1994).

Given the evidence for MT's role in motion perception, it is natural to ask if MT plays the same role in second-order motion perception. Albright (1992) briefly reported that most MT neurons retained directionality when tested with second-order motion, but this question has otherwise remained unexplored. We have now made detailed comparisons of MT neuronal responses to first- and second-order motion, and a similar comparison for a smaller sample of V1 neurons. We wanted to know whether area MT represents the neural substrate for the second-order motion mechanism in the same way it does for the first-order mechanism. We found that most neurons in MT respond poorly and nonselectively to second-order motion stimuli. Those few neurons giving vigorous and selective responses to second-order motion targets did not appear to be distinct from other MT neurons with respect to receptive-field eccentricity, component-pattern direction selectivity, or spatio-temporal tuning properties. They were distinct only in that they were slightly more responsive and more sensitive to stimulus contrast than other MT neurons. Area MT's main functions may concern the analysis of first-order motion, with other kinds of motion processing largely done elsewhere in the visual cortex.

\section{Materials and methods}

\section{Surgical preparation}

The procedures used for single-unit recordings from the cortex of acutely prepared, anesthetized, paralyzed macaque monkeys have been described in detail elsewhere (Levitt et al., 1994). Experi- ments were performed on nine adult cynomolgus (Macacca fascicularis) monkeys ranging in weight from 3.5 to $4.5 \mathrm{~kg}$. Animals were premedicated with Atropine sulfate $(0.05 \mathrm{mg} / \mathrm{kg})$ and Acepromazine malleate $(0.05 \mathrm{mg} / \mathrm{kg})$ and initially anesthetized with Ketamine HCL $(10 \mathrm{mg} / \mathrm{kg})$. Anesthesia continued on $1.5-2.0 \%$ halothane in a $98 \% \mathrm{O}_{2}-2 \% \mathrm{CO}_{2}$ mixture while the initial surgery was performed. Indwelling catheters were introduced into the saphenous veins of each hindlimb, a urinary catheter was inserted, and a tracheotomy performed. The animal was then mounted in a stereotaxic instrument. Vital signs (including EEG, EKG, end-tidal $\mathrm{PCO}_{2}$, temperature, and lung pressure) were monitored continuously. Halothane anesthesia was then discontinued, and a continuous infusion of sufentanil citrate (typically $4-6 \mu \mathrm{g} / \mathrm{kg} / \mathrm{h}$ ) was begun following a loading dose of $4 \mu \mathrm{g} / \mathrm{kg}$ (the rate was determined for each animal during a stabilization period prior to the induction of systemic paralysis, and monitored using conventional assessments based on EEG, EKG, and autonomic signs). At this point, the monkey was artificially respired with room air or with a mixture of $\mathrm{O}_{2}: \mathrm{N}_{2} \mathrm{O}$ (typically 50:50). End-tidal $\mathrm{PCO}_{2}$ was maintained at $3.8-4.0 \%$.

The scalp was opened via a midline incision and the muscles reflected back to expose the skull. A craniotomy was performed and the surface of the cortex between the intraparietal sulcus and the superior temporal sulcus was exposed (at approximately HC P 2.0, L 16.0). A hydraulic microdrive containing a tungsten-in-glass electrode inside a $21 \mathrm{G}$ guide tube was lowered into position about 3-4 $\mathrm{mm}$ posterior to the postcentral sulcus at L 15.5. A plastic chamber was constructed to surround the electrode and guide tube and was filled with a $4 \%$ agar in sterile saline solution. In one experiment, we recorded in V1, inserting the electrode through a similar craniotomy and durotomy made over the dorsal surface of the occipital lobe. At the completion of all surgical procedures, a continuous infusion of muscle relaxant was begun (Norcuron, 0.1 $\mathrm{mg} / \mathrm{kg} / \mathrm{h}$, loading dose of $0.1 \mathrm{mg} / \mathrm{kg}$ ). The monkey was fitted with $+2 \mathrm{D}$ gas-permeable contact lenses; supplementary lenses were used as necessary to make the retinas conjugate with the face of a display placed (in different experiments) between 73 and $163 \mathrm{~cm}$ distant. To maintain the animal in good physiological condition during experiments (typically 72-96 h), intravenous supplementation of $2.5 \%$ dextrose/lactated Ringer's was given at $5.0 \mathrm{ml} / \mathrm{h}$; an anti-inflammatory agent (dexamethasone) and a broad-spectrum antibiotic (Bicillin) were given daily.

\section{Recording}

Recordings were made using tungsten-in-glass microelectrodes (Merrill \& Ainsworth, 1972). Signals from the microelectrode were amplified $(10,000 \times)$, bandpass-filtered $(300 \mathrm{~Hz}-10 \mathrm{kHz})$, and fed into a hardware window discriminator and an audio monitor. The discriminator's output was fed into the digital input port of an intelligent lab interface, along with synchronization signals from the video graphics board. The lab interface collected standard pulses triggered by each action potential and assembled them into conventional averaged response histograms. Data were analyzed online and used to determine subsequent stimulus presentations.

\section{Visual stimuli}

Stimulus presentation and data acquisition were controlled by an IBM PC compatible computer. Stimuli were generated by a Truevision ATVista board operating at a resolution of $752 \times 582$ pixels and a frame rate of $106 \mathrm{~Hz}$ whose gamma-corrected output was 
directed to a BARCO CDCT 7351 monitor (mean luminance 36.5 $\mathrm{cd} / \mathrm{m}^{2}$ ), and later to a Nanao T560i (mean luminance $72 \mathrm{~cd} / \mathrm{m}^{2}$ ). The width of the screen varied between 10.4 and $24.5 \mathrm{deg}$ in different experiments. Standard stimuli consisted of sinusoidal gratings whose size, location, spatiotemporal and chromatic properties were under the control of the experimenter.

\section{Second-order motion stimuli}

Chubb and Sperling $(1988,1989)$ described methods for generating various classes of second-order motion stimuli. In general, the stimuli are created by modulating the contrast, temporal structure, or spatial structure of an underlying random carrier, and then moving the modulator while leaving the carrier stationary. Fig. 1 shows $x-t$ representations of the first- and second-order motion stimuli used in the experiments.

Fig. 1A shows an $x-t$ representation of a rightward drifting sinusoidal first-order grating. Each row of pixels represents a horizontal slice through the center of each frame of the image sequence, with slices stacked top to bottom over time. By tracking the orientation of the light and dark regions, an observer can de- duce that the plot represents movement of the grating to the right. The motion of this type of display is cued by luminance and is therefore first order. Fig. 1B shows an $x-t$ representation of a second-order motion stimulus consisting of a rightward drifting sinusoid modulating the contrast of a static, two-dimensional texture whose pixel elements which were assigned values drawn from a Bernoulli distribution with $P=0.5$. The motion of this stimulus is cued by contrast; the expected luminance within any arbitrarily defined region of this $x-t$ plot is uniform (it is microbalanced, in the terminology of Chubb and Sperling, 1988, 1989). We used a version of this stimulus in early experiments, but found it difficult to escape contamination by luminance artifacts at high contrasts. We therefore abandoned this stimulus in favor of the one shown in Fig. 1C, which consists of a random two-dimensional spatial texture (like that described above) whose temporal structure is modulated by a drifting square wave. The flicker rate of the peak of the square-wave modulator was typically $53 \mathrm{~Hz}$ (but adjustable), while the flicker rate at the trough of the square-wave modulator was fixed at $0 \mathrm{~Hz}$. Because this stimulus contains the same two luminance levels in both the static and flickering regions, it is free from luminance artifacts even if monitor calibration is imperfect. The
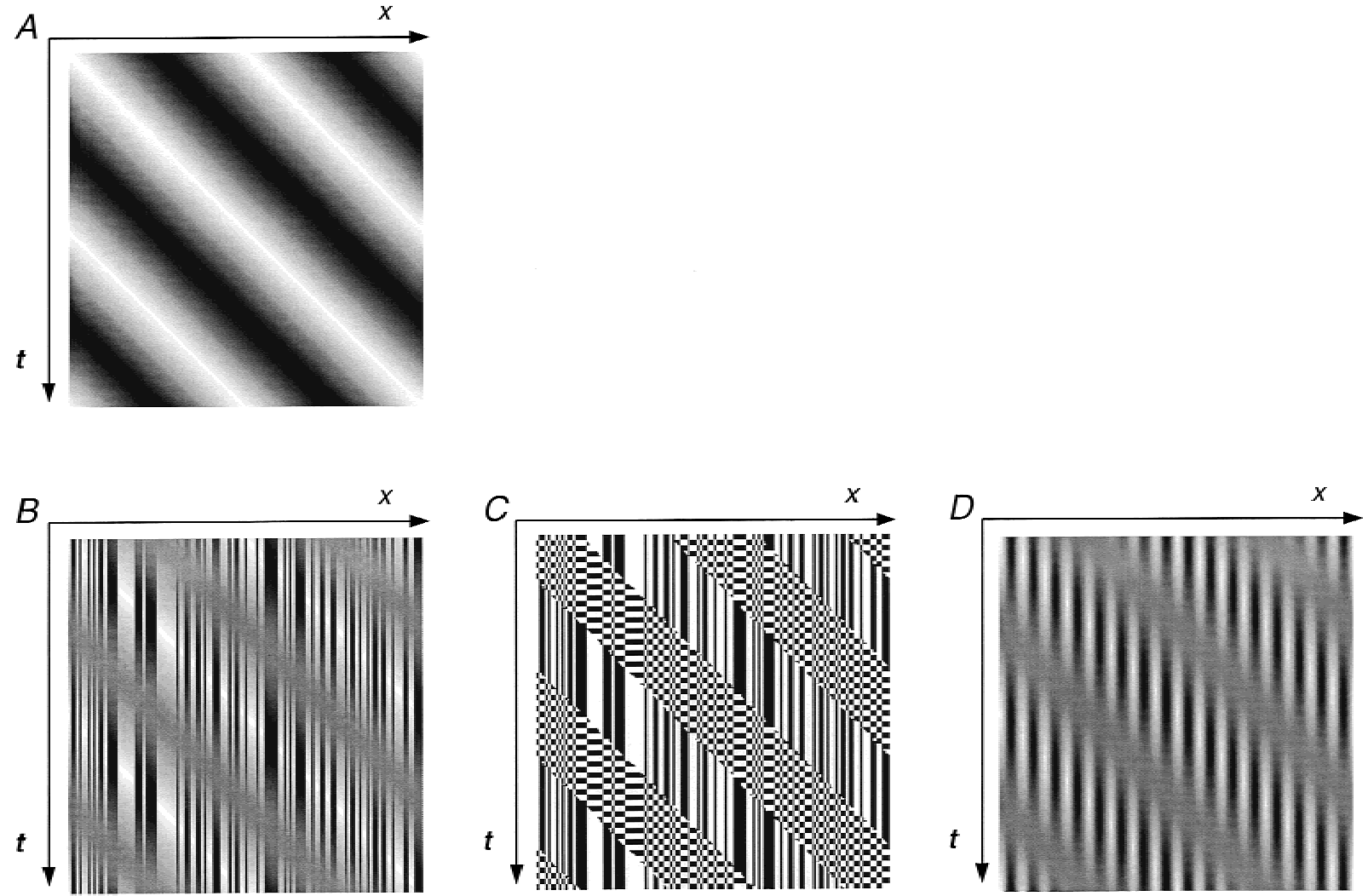

Fig. 1. $x-t$ plots of first-order and second-order motion stimuli. All stimuli illustrated here were vertically oriented and drifting rightward. The rightward motion is represented by the diagonal orientation in space-time. A: $x-t$ plot of a drifting sinusoidal grating. The $x$ dimension is a horizontal slice taken from one frame of the grating sequence. The $y$ dimension represents time starting at the top and progressing downward. B: $x-t$ plot of a drifting contrast-modulated second-order grating. The stimulus was created by sinusoidally modulating the contrast of a two-dimensional static texture. C: $x-t$ plot of a drifting flicker-modulated second-order grating. The flicker frequency of the static two-dimensional binary noise (indicated by the black and white bar regions) was modulated by a drifting square wave (indicated by the checked regions). D: $x-t$ plot of a drifting second-order "envelope" stimulus. The stimulus was created by sinusoidally modulating the contrast of a stationary sinusoid. In B, C, and D, orientation in space-time can be observed by segregating the texture regions but cannot be observed by comparing luminance, since the average luminance in all regions is identical. 
motion of this stimulus is cued not by luminance but by flicker; the expected luminance within an arbitrary $x-t$ window is uniform. Therefore, the motion of this stimulus (and the one in Fig. 1B) cannot be recovered by first-order mechanisms. Fig. 1D shows a representation of a different class of second-order motion stimulus, an "envelope" stimulus consisting of a drifting contrast modulation of a high-spatial-frequency sinusoidal grating carrier used in some earlier studies of visual cortex of cat and monkey (Albrecht \& De Valois, 1981; Zhou \& Baker, 1993, 1994). This stimulus is secondorder, since the motion is cued by contrast, not luminance, but it is not microbalanced (Fleet \& Langley, 1994). We studied the responses of a small number of MT neurons to this type of stimulus.

\section{Receptive-field mapping and classification}

The fovea of each eye was plotted on a plotting table with a reversible ophthalmoscope. Receptive fields of isolated neurons were mapped with slits of light on the plotting table and were then projected onto the face of the monitor by means of a front-surface mirror. We used quantitative techniques to determine each neuron's stimulus preferences. First, direction tuning was assessed by presenting drifting, sinusoidal gratings whose direction spanned $360 \mathrm{deg}$ in 30-deg steps. We then measured spatial-frequency tuning in the preferred direction and temporal-frequency tuning in the preferred direction at the preferred spatial frequency; in most cells, we also measured contrast response. We measured responses as a function of stimulus area; if the neuron's response was suppressed by stimuli presented outside the classical receptive field, we restricted the size of the stimuli with a contrast window that presented unmodulated midgray background to the periphery of the receptive field. After finding the optimal stimulus parameters for first-order gratings, we studied the neuron's response to secondorder gratings. Initially, we set the parameters to match those obtained for the first-order gratings and made a subjective assessment of the neuron's response. If response to the second-order gratings was weak, we attempted to reoptimize stimulus parameters, notably texture size (typically 2 min arc, but adjustable to 1, 2, 4, or $8 \mathrm{~min}$ arc) spatial frequency, temporal frequency (from $\sim 0.2-$ $13.25 \mathrm{~Hz}$ in octave steps), and to some extent, flicker rate (typically $53.0 \mathrm{~Hz}$, but adjustable from $\sim 6.12-53.0 \mathrm{~Hz}$ in octave steps). When we were satisfied with the selected parameters, we ran a direction tuning experiment on the cell. If the neuron gave little or no response to our initial set of second-order parameters, it generally gave no better response to parametrically different secondorder targets. If the neuron responded reliably to second-order motion, we measured spatial- and temporal-frequency tuning and contrast response (by manipulating the Michelson contrast of the carrier pixels) for the second-order gratings.

\section{Quantitative measures}

Our response measure was of net mean firing rate (for MT cells and V1 complex cells) or response modulation at the stimulus temporal frequency (for V1 simple cells), based on 3-6 randomly interleaved repeats of 2-4 s presentations of each stimulus. Mean baseline responses to a uniform mean luminance stimulus were subtracted from the response to each stimulus for MT cells and V1 complex cells. For most measures (spatial frequency, temporal frequency, contrast response), we fit descriptive functions to the data (Levitt et al., 1994) to compute estimates of optima and tuning bandwidths.

\section{Component-pattern classification}

We also compared responses to drifting gratings with responses to drifting plaid patterns composed of the sum of two gratings whose direction of motion differed by $120 \mathrm{deg}$, to permit classification as pattern- or component-direction selective (Movshon et al., 1985). We predicted the response of a component-direction-selective cell to a plaid pattern by shifting a copy of the grating response so that it matched the direction of each component of the plaid pattern. We then computed partial correlations between the response to the plaid $\left(R_{p}\right)$ and the response to the component gratings $\left(R_{c}\right)$ (Movshon et al., 1985; Movshon \& Newsome, 1996). We classified neurons as pattern-direction selective if $R_{p}>R_{c}$, and as componentdirection selective otherwise.

\section{Selectivity measures}

To characterize a neuron's selectivity for direction or orientation independent of response magnitude, we calculated direction and orientation biases (Levick \& Thibos, 1982; Leventhal et al., 1995). We treated each response (baseline subtracted for MT cells and V1 complex cells) as a vector whose length is the response magnitude and whose angle is the direction or twice the orientation of the stimulus. We divided the vector sum by the sum of the absolute values of the vectors (Leventhal et al., 1995). The index provided an estimate of preferred direction or orientation and selectivity (sharpness of tuning) that was independent of response amplitude. A direction or orientation bias of 1.0 indicates "perfect" selectivity (response to only a single orientation or direction), while a bias of 0.0 indicates complete absence of selectivity (equal response to all directions/orientations). We estimated the significance of each bias estimate by a permutation technique. For each data set, we ran 2000 permutations of the data through the bias analysis and constructed distributions of the resulting estimates. We defined a data set as showing significant bias if the measured bias exceeded the 90th percentile of the permuted bias distribution. We chose this relatively loose criterion to include data from as many neurons as possible in our analysis of selectivity. A neuron that was highly orientation selective but not direction selective would have a low direction bias and a high orientation bias, so we computed both selectivity indices for each neuron and if both indices were significant, selected the larger of the two bias indices as a measure of selectivity. We thus determined whether each neuron was selective for the direction or orientation of first-order motion, and compared that selectivity to the same measure of selectivity for second-order motion.

\section{Results}

We measured direction tuning for both first- and second-order gratings in 207 MT neurons in nine monkeys, and 34 V1 neurons in one monkey. We collected spatial- and temporal-frequency tuning data for first-order gratings from all of these neurons, and collected contrast-response functions and area tuning data from most. For neurons that responded to second-order gratings in the direction tuning tests, we measured spatial- and temporal-frequency tuning and contrast-response functions for the second-order gratings.

Receptive fields of MT neurons were centered within $20 \mathrm{deg}$ of the fovea, with the majority (148 of 207) having receptive fields centered within 6 deg of the fovea. Receptive fields of V1 neurons were all centered within $3 \mathrm{deg}$ of the fovea.

Fig. 2 shows direction tuning data collected from eight representative MT neurons. Responses to first-order motion are plotted 
A
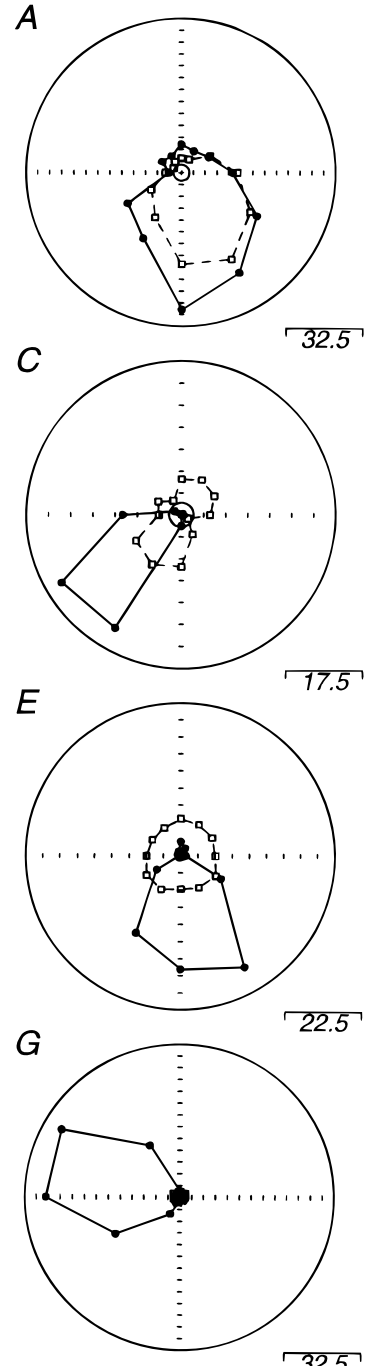

$B$

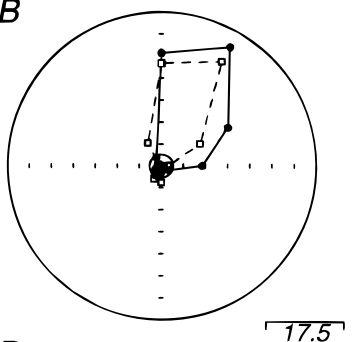

$D$

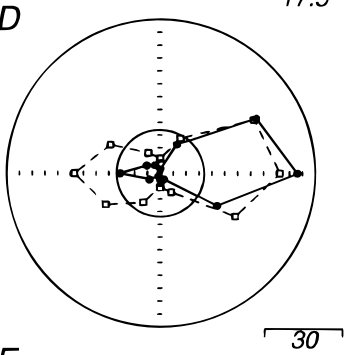

30
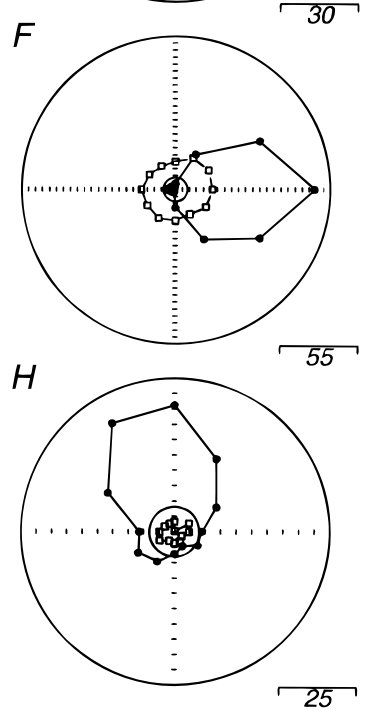

Fig. 2. Direction tuning of MT neurons for first-order (filled circles) and second-order (open squares) motion. Stimulus direction is represented by polar angle and response is represented by distance from the origin. Solid circles indicate average baseline discharge. Calibration bars show response rate for each cell. A, B: Data from two neurons that had similar directional tuning for first- and second-order motion. C, D: Data from two neurons that were less direction selective for second-order motion than for first-order motion. E, F: Data from two neurons that showed nonselective responses to second-order motion. G, H: Data from two MT neurons that gave no responses to second-order motion, but brisk responses to first-order motion.

with filled symbols connected by solid lines; responses to secondorder motion are plotted with open symbols connected by dashed lines.

Nearly all cells were responsive and selective for first-order motion, while responsiveness and selectivity for second-order motion varied widely. Figs. $2 \mathrm{~A}$ and $2 \mathrm{~B}$ show data from two MT neurons whose directional tuning for first- and second-order gratings was similar. Figs. $2 \mathrm{C}$ and $2 \mathrm{D}$ show example data from two MT neurons that were less selective for second-order gratings than for first-order gratings. The reduced selectivity for second-order motion was due in part to decreased responses in the preferred direction and in part to increased responses in the null direction. Figs. 2E and 2F show example data from two MT neurons that gave direction-selective responses to first-order gratings and non-

selective responses to second-order gratings. Most cells in our sample behaved like the neurons illustrated in Figs. $2 \mathrm{G}$ and $2 \mathrm{H}$, giving vigorous, direction-selective responses to first-order gratings and little or no response to second-order gratings.

\section{Response strength}

For the vast majority of MT and V1 neurons, second-order gratings were less effective than first-order gratings. This is illustrated in Fig. 3, which plots the net response evoked by first-order gratings against the net response evoked by second-order gratings for MT cells (Fig. 3A) and V1 cells (Fig. 3B). The majority of the data (93\% and $88 \%$ for MT and V1 cells, respectively) fall below the diagonal indicating equal responses. There was a significant correlation between responses to first- and second-order motion for both MT $(r=0.597, P<0.0001)$ and V1 $(r=0.503, P<0.0025)$ neurons. Fig. 3 also shows a marginal distribution of the ratio of responses to first- and second-order motion. The geometric mean of the distribution was 4.5 for MT cells and 5.4 for V1 cells. Only 17 of 207 MT neurons and three of 34 V1 neurons responded as well to second-order motion as they did to first-order motion.

\section{Selectivity}

The responses of MT and V1 neurons to first- and second-order motion usually differed, both in response strength and in the shape of the direction tuning curve (Fig. 2). Cells that were direction selective for first-order motion were frequently orientation selective (e.g. Figs. 2C and 2D) or nonselective (e.g. Figs. 2E and 2F) for second-order motion. In V1, most cells were orientation selective for first-order motion, and nonselective for second-order motion. To compare tuning for first- and second-order motion, we took the greater of direction or orientation bias as the cell's selectivity for first-order motion, and compared that to the same selectivity to second-order motion; we counted neurons as selective if the value of their bias index achieved a significance level of 0.1 on a permutation test (see Materials and methods).

Fig. 4 shows the relationship between selectivity for first-order gratings and selectivity for second-order gratings for MT (Fig. 4A) and V1 (Fig. 4B) neurons. About 24\% of our MT sample (49/207) exhibited significant selectivity for both first- and second-order motion (Fig. 4A, filled circles); of the remainder (Fig. 4A, open circles), 71\% (148/207) were selective for first- but not secondorder motion, $1 \%(3 / 207)$ were selective for second- but not firstorder motion, and $3 \%$ (7/207) were not selective for either type of motion. About $9 \%$ of our V1 sample (3/34) exhibited significant selectivity for both first- and second-order motion (Fig. 4B, filled circles); of the remainder (Fig. 4B, open circles), $88 \%(30 / 34)$ were selective for first- but not second-order motion and one cell was selective for second- but not first-order motion. Nearly all MT (197/207, 95\%) and V1 neurons (33/34, 97\%) were selective for first-order motion; about one quarter of the MT (52/207, 25\%) and V1 neurons $(9 / 34,26 \%)$ were selective for second-order motion. There was no correlation between selectivity for first- and secondorder motion in MT or V1. Of the cells with significant selectivity, $22 \%(11 / 49)$ of our MT sample and none of the V1 sample showed equal or greater selectivity for second-order motion; most neurons had substantially greater selectivity for first-order motion.

We wanted to know what proportion of our samples could potentially provide a behaviorally relevant signal-i.e. what proportion of our samples were both selective and responsive for a 

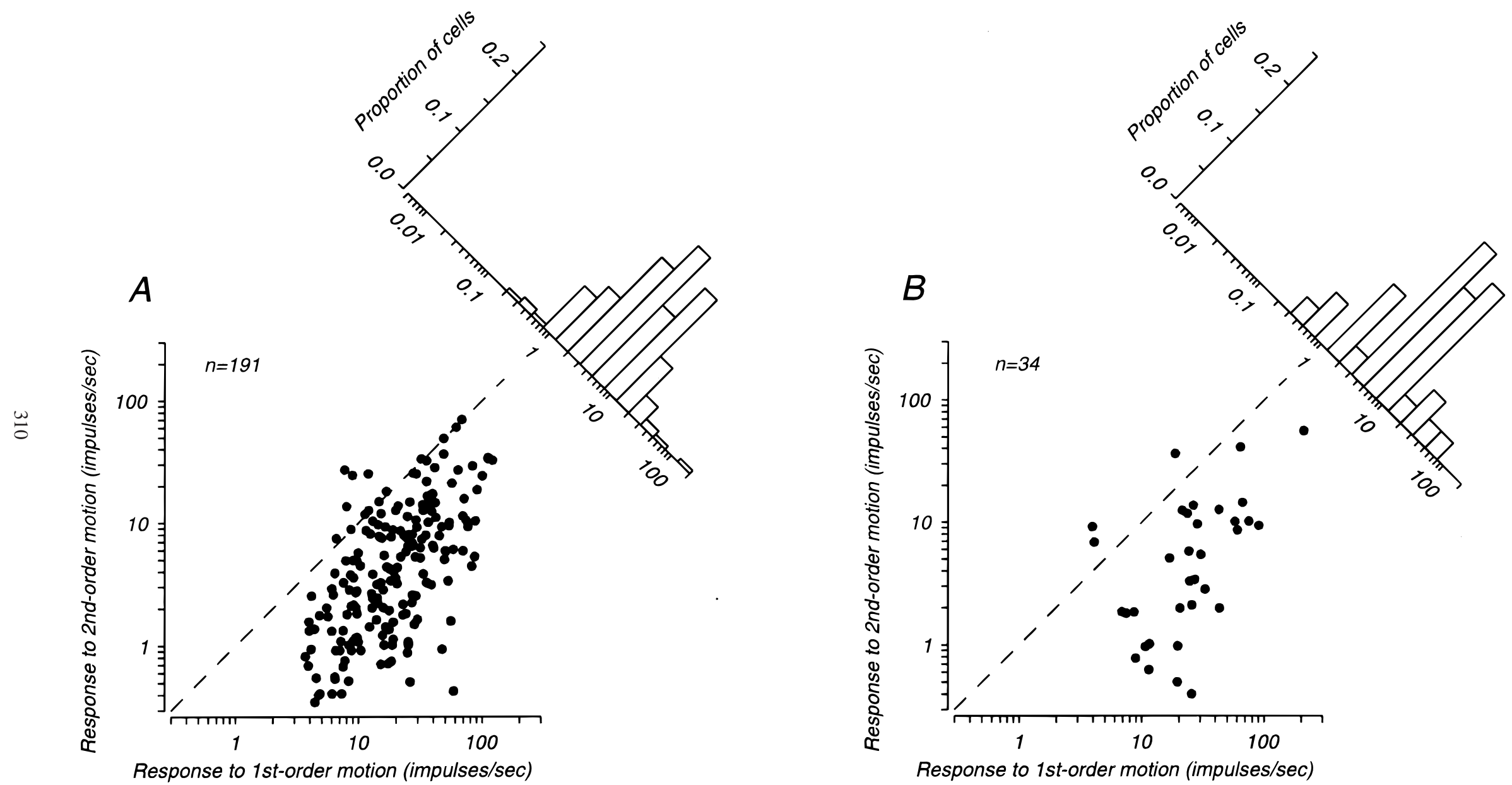

Fig. 3. Comparison of response strength for first-order and second-order gratings. Data are net responses (i.e. maximum response minus baseline). Marginal distributions show the ratio of responses to first- and second-order motion. A: Data from 191 MT neurons; 16 neurons had zero net response to second-order motion. B: Data from 34 V1 neurons. 

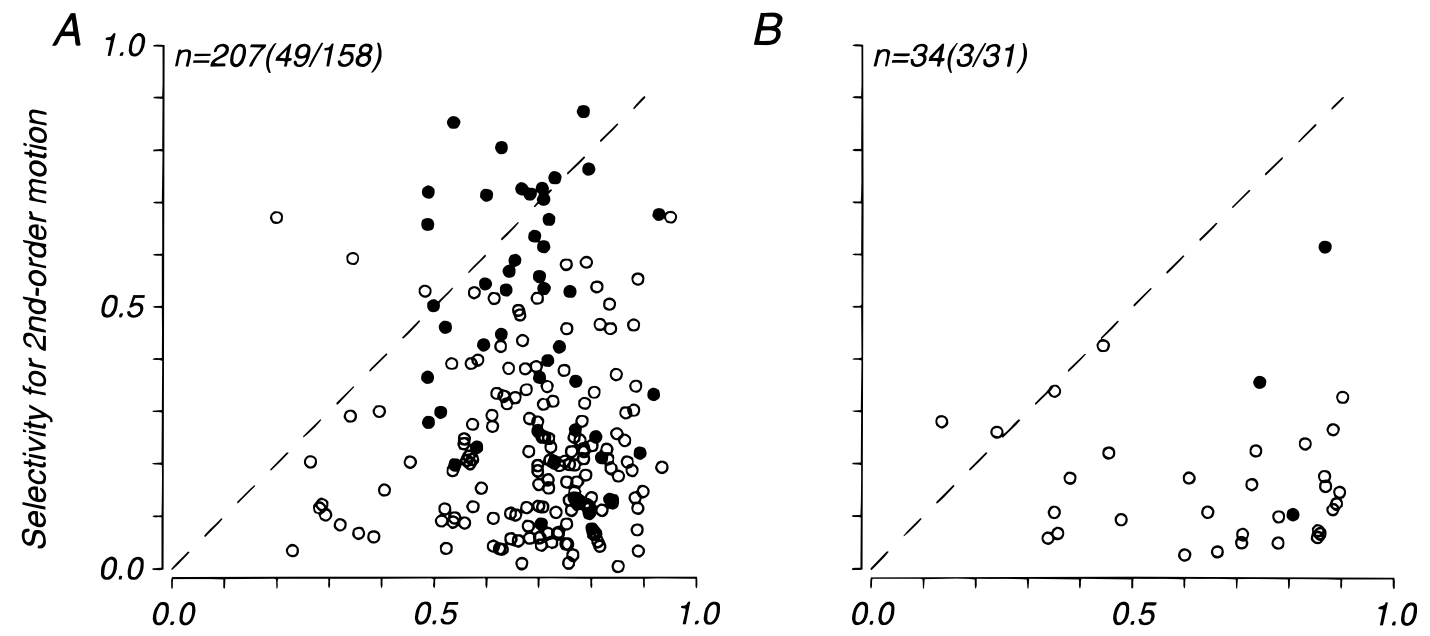

Selectivity for 1st-order motion

Fig. 4. Comparison of selectivity for first-order and second-order gratings. Filled circles represent cells with significant selectivity for both first- and second-order motion. Open circles represent cells that lacked significant selectivity for either first- or second-order motion. A: Data from 207 MT cells, 49 of which showed significant selectivity for both first- and second-order motion. B: Data from $34 \mathrm{~V} 1$ cells, three of which showed significant selectivity for both first- and second-order motion.

particular type of motion signal. In Fig. 5, we plot each cell's selectivity against its response for first-order motion (top panel) and second-order motion (bottom panel). The dashed lines arbitrarily divide the plots into quadrants to help visualize differences in the distributions of data for the two stimuli. The proportion of cells falling in each quadrant is indicated to the lower right of each plot. Nearly two thirds $(62 \%)$ of our sample of MT neurons fell into the upper-right quadrant when tested with first-order motion;
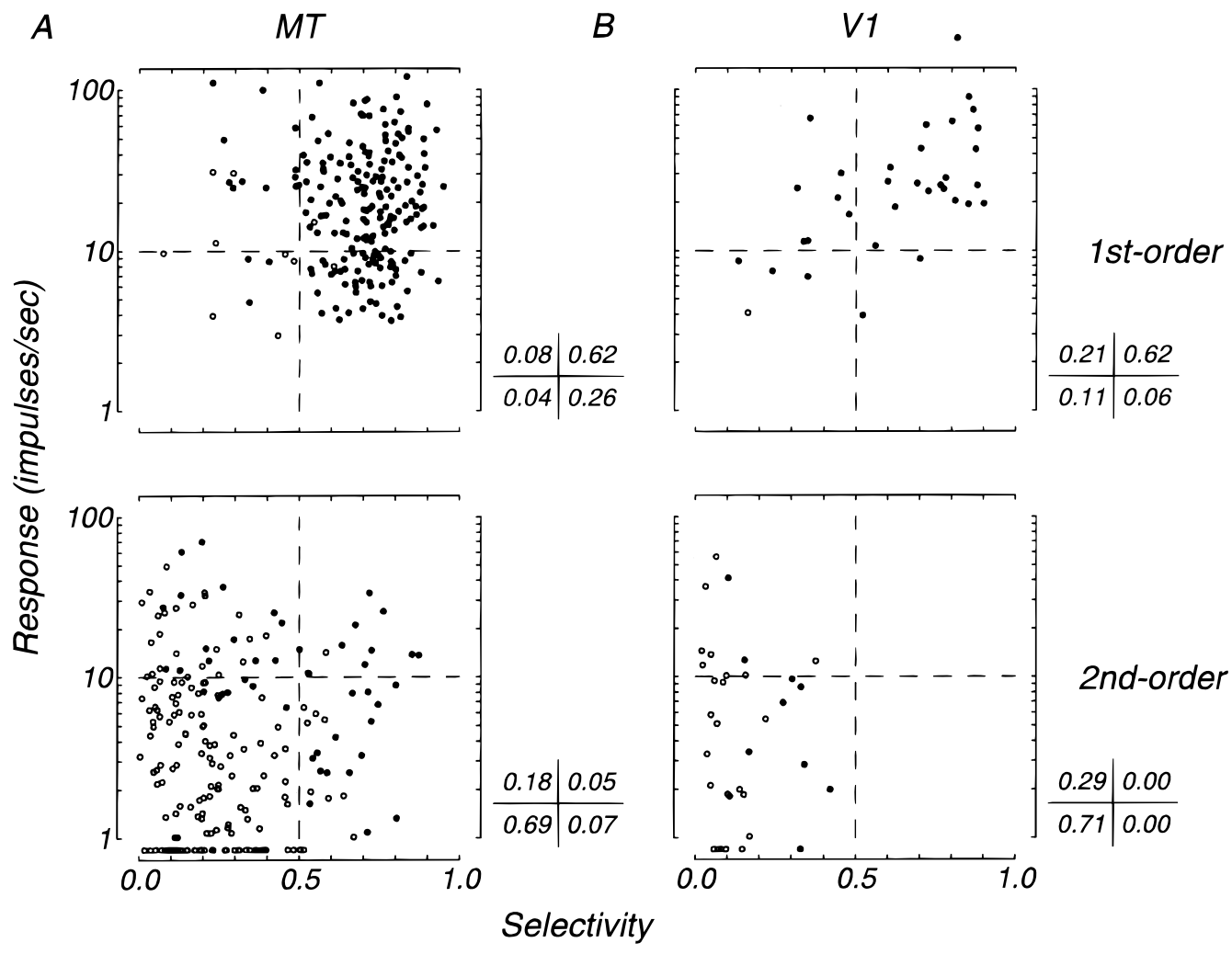

Fig. 5. Relationship between response and selectivity for first-order motion (top panels) and second-order motion (bottom panels). Symbols are as in Fig. 4. Insets show proportion of sample falling into each quadrant of the plot (defined by dashed lines). A: Data from MT neurons. B: Data from V1 neurons. 
only $5 \%$ fell into the upper-right quadrant when tested with secondorder motion (Fig. 5A). A similar proportion of our V1 sample fell into the upper-right quadrant when tested with first-order motion; however, none fell into the upper-right quadrant when tested with second-order motion (Fig. 5B). Thus, only a small minority of the neurons we studied were both selective for and responsive to secondorder motion.

\section{Tuning properties of cells selective for second-order motion}

For neurons that responded reliably to second-order motion in the direction tuning experiments, we measured spatial tuning, temporal tuning, and contrast response for suitable second-order targets. Fig. 6 shows the data for a single MT neuron (the neuron whose direction tuning data are shown in Fig. 2B). We measured spatial-frequency tuning (Fig. 6A) for both first- and second-order gratings and fit the data with a descriptive function (solid line) to estimate preferred spatial frequency and bandwidth. This neuron's tuning curve for second-order gratings was shifted down in both amplitude and spatial frequency compared to that for first-order gratings. We then measured temporalfrequency tuning at the optimal spatial frequency (Fig. 6B) and fit the data with a descriptive function (solid line) to estimate preferred temporal frequency and bandwidth. This neuron showed similar temporal-frequency tuning for first- and second-order motion, though response amplitude for the second-order gratings was lower than that for the first-order gratings. We measured contrast responses (Fig. 6C) in the usual way for first-order gratings, but for the second-order stimuli, we manipulated the contrast of the pixels of the binary texture carrier. This neuron had different contrast responses for first- and second-order motion; for first-order gratings, the response exceeded baseline for contrasts above 0.06, while for second-order gratings, no contrast below 0.5 was effective in driving the cell.

We compared the orientation/direction tuning, spatial-frequency tuning, temporal-frequency tuning, and contrast response for firstand second-order motion for the 49 MT neurons that showed significant selectivity for both stimuli. Our V1 sample was insufficient (only 3 cells) for these comparisons.

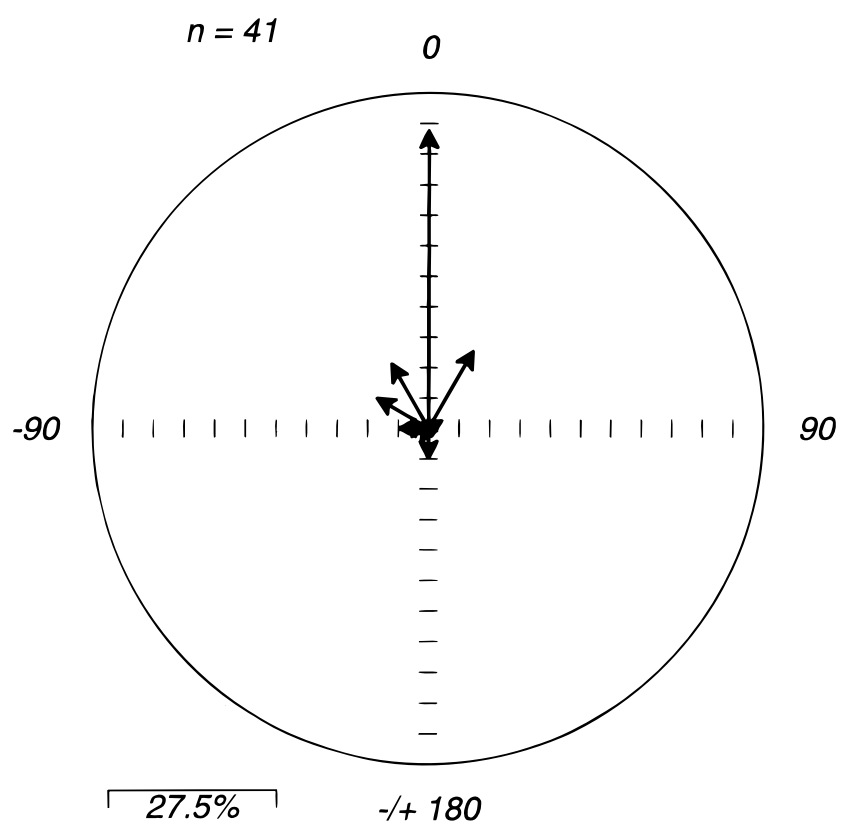

Fig. 7. Polar distribution of the difference in preferred direction for firstand second-order motion for the MT neurons that were selective for both first- and second-order motion. Polar angle represents direction difference (30-deg bins), distance from the origin represents percentage of the sample falling into each bin. Calibration bar indicates half the radius of the plot, $27.5 \%$.

\section{Direction/orientation tuning}

For each cell, we calculated the difference in preferred direction for first- and second-order gratings. Fig. 7 shows a polar distribution of these data. In this plot, polar angle represents difference in preferred direction and distance from the origin represents percentage of the sample. Just under half of our MT sample that was selective for second-order motion had direction preferences for first- and second-order motion that differed by less than $30 \mathrm{deg}$.
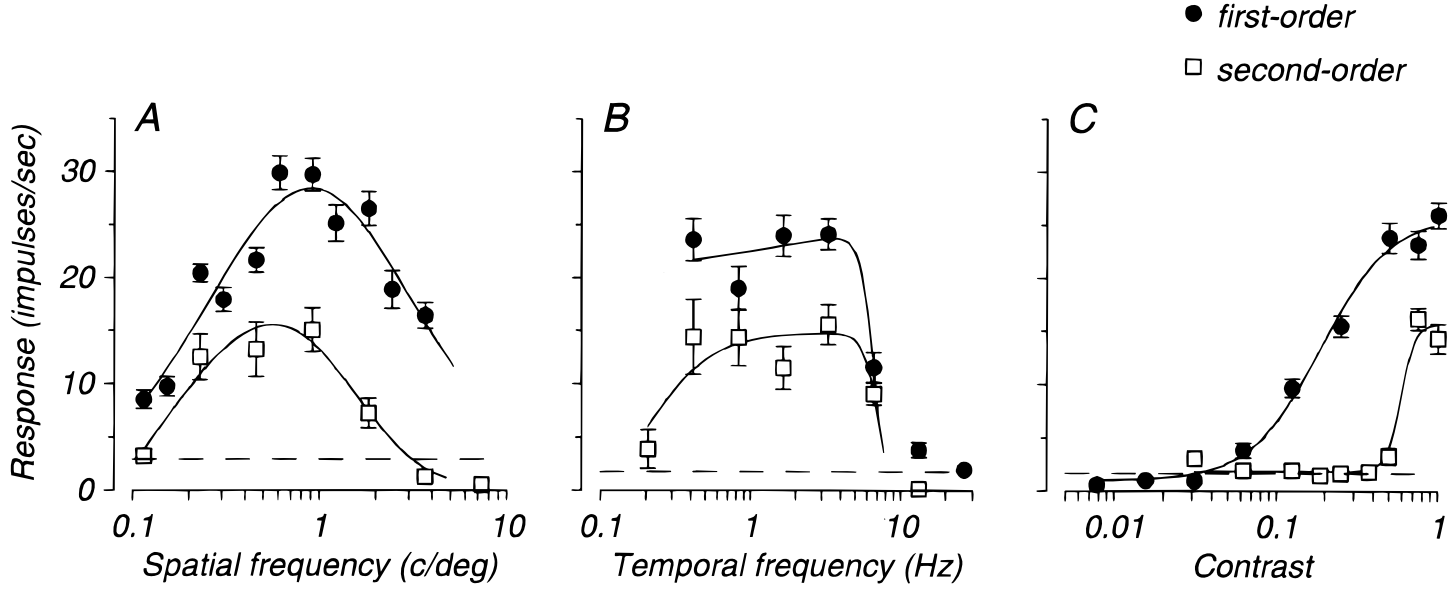

Fig. 6. Tuning properties of one MT neuron for first- and second-order motion. Symbols are as in Fig. 2. Solid lines are the fits of descriptive functions used to estimate tuning parameters. Baseline activity is indicated by dashed lines. Error bars are \pm 1 standard error of the mean. A: Spatial-frequency tuning. B: Temporal-frequency tuning. C: Contrast response. 
We made the same computation for the eight cells in our sample that were orientation selective for both first- and second-order motion and found similar results; seven of eight cells had orientation preferences that differed by less than $30 \mathrm{deg}$.

\section{Spatial-frequency tuning}

We were able to measure spatial-frequency tuning for both firstand second-order gratings in $37 \mathrm{MT}$ neurons. Fig. 8A shows the relationship between preferred spatial frequency, and Fig. 8B shows the relationship between spatial-frequency tuning bandwidth (in octaves) for first- and second-order gratings. Six cells preferred spatial frequencies below 0.1 cycle/deg for either first- or secondorder gratings (open circles). For the remaining cells, there was a significant correlation between preferred spatial frequencies for first- and second-order motion (Fig. 8A) $(r=0.645, P=0.0001)$. We did not estimate spatial-frequency tuning bandwidths for the 15 neurons that exhibited low-pass tuning (i.e. the response to the lowest spatial frequency was greater than half of the response to the preferred spatial frequency-open circles in Fig. 8B). For the remaining cells, spatial-frequency tuning bandwidths for first- and second-order motion were uncorrelated.

\section{Temporal-frequency tuning}

We were able to measure temporal-frequency tuning for both firstand second-order gratings in $32 \mathrm{MT}$ neurons. Fig. 8C shows the relationship between preferred temporal frequency for first- and second-order gratings. Six cells preferred temporal frequencies below $0.3 \mathrm{~Hz}$ for either first- or second-order gratings (Fig. 8C, open circles). The rest of the neurons preferred lower temporal frequencies for second-order motion than for first-order motion $[t(50)=4.34, P<0.0001]$. The preferred temporal frequencies for first- and second-order motion were uncorrelated-one could not predict a neuron's preferred temporal frequency for secondorder motion from its preferred temporal frequency for first-order motion, other than to say that it would be lower.

\section{Contrast response}

We were able to measure contrast responses for both first- and second-order motion in 12 MT neurons. Fig. 9 shows the relation- ships between $\mathrm{C}_{50}$, (contrast evoking half-peak response) (Fig. 9A) and contrast threshold (contrast evoking 1 impulse/s above baseline firing) (Fig. 9B) for first- and second-order gratings, estimated from fits of a hyperbolic ratio function to the data (Albrecht \& Hamilton, 1982). Peak response (not shown) for first- and secondorder gratings was well correlated $(r=0.777, P<0.003)$, as was expected (given that responsiveness for first- and second-order gratings was correlated in the direction tuning experiments). Both $\mathrm{C}_{50}[t(22)=4.4, P=0.0001]$ and contrast threshold $[t(20)=$ 5.89, $P<0.0001]$ were significantly higher for second-order than for first-order gratings (Figs. 9A and 9B). Neither $\mathrm{C}_{50}$ nor contrast threshold for second-order motion was correlated with that for first-order motion.

What receptive-field properties predict selectivity for second-order motion?

We compared the distributions of receptive-field center eccentricity, pattern selectivity, direction selectivity, spatial- and temporalfrequency tuning, and contrast-response parameters for the 49 neurons that showed selectivity for second-order motion with those for the remainder of our MT sample to determine if cells that were selective for second-order motion could be distinguished on the basis of standard receptive-field properties. The only receptivefield properties that distinguished cells selective for second-order motion from the rest of the sample were contrast sensitivity and, to a lesser extent, spatial tuning bandwidth. Cells selective for secondorder motion had smaller $\mathrm{C}_{50} \mathrm{~s}[t(111)=2.28, P=0.024]$, lower contrast thresholds $[t(116)=2.94, P=0.004]$, and marginally broader spatial bandwidths $[t(169)=2.05, P<0.05]$ than the rest of the sample. We found no relationship between receptive-field eccentricity or pattern-direction selectivity and selectivity for secondorder motion.

\section{Responses to different types of second-order motion}

Zhou and Baker $(1993,1994)$ reported that more than half of the neurons in cat area 18 and a minority of neurons in cat striate cortex were responsive to second-order "envelope" stimuli in which the contrast of a stationary (high spatial frequency), sinusoidal grating carrier was modulated by a drifting (low spatial frequency) sinusoidal contrast envelope (Fig. 1D). When the spatial frequency
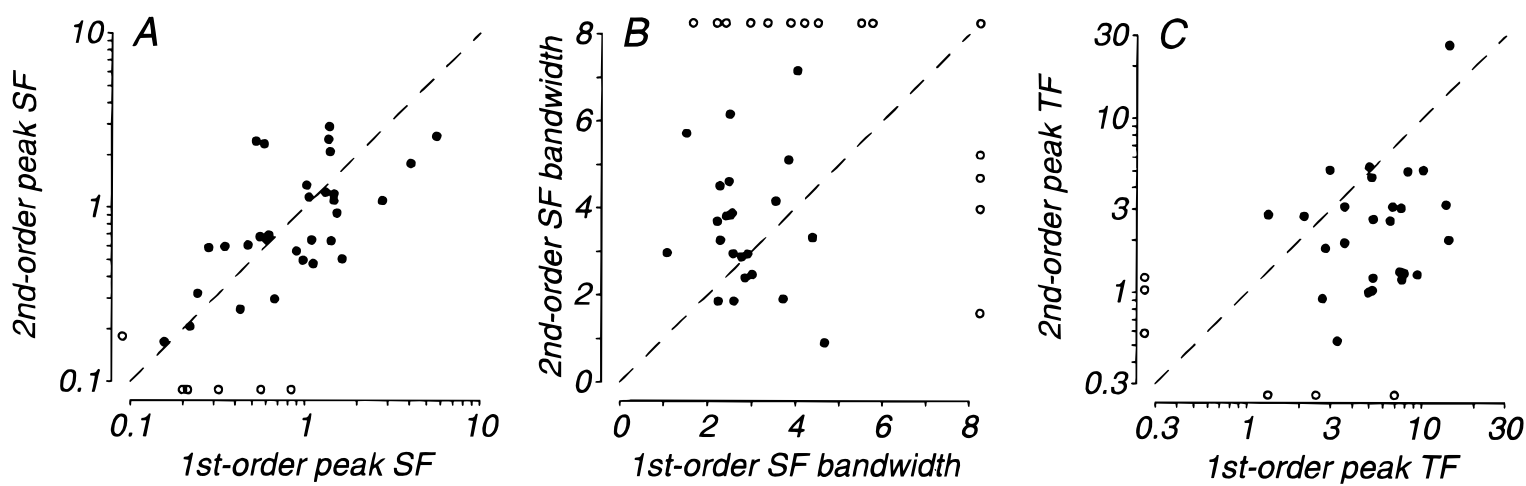

Fig. 8. Comparison of spatial- and temporal-frequency tuning for first-order and second-order gratings for the MT neurons that were selective for both first- and second-order motion. The dashed line indicates identical preferences for the two stimuli. A: Preferred spatial frequency. Open circles indicate cells with a preferred spatial frequency below 0.1 cycle/deg. B: Spatial-frequency bandwidth (octaves). Open circles indicate cells with low-pass spatial-frequency tuning, for which bandwidth could not be estimated. C: Preferred temporal frequency. Open circles indicate cells with a preferred temporal frequency below $0.3 \mathrm{~Hz}$. 

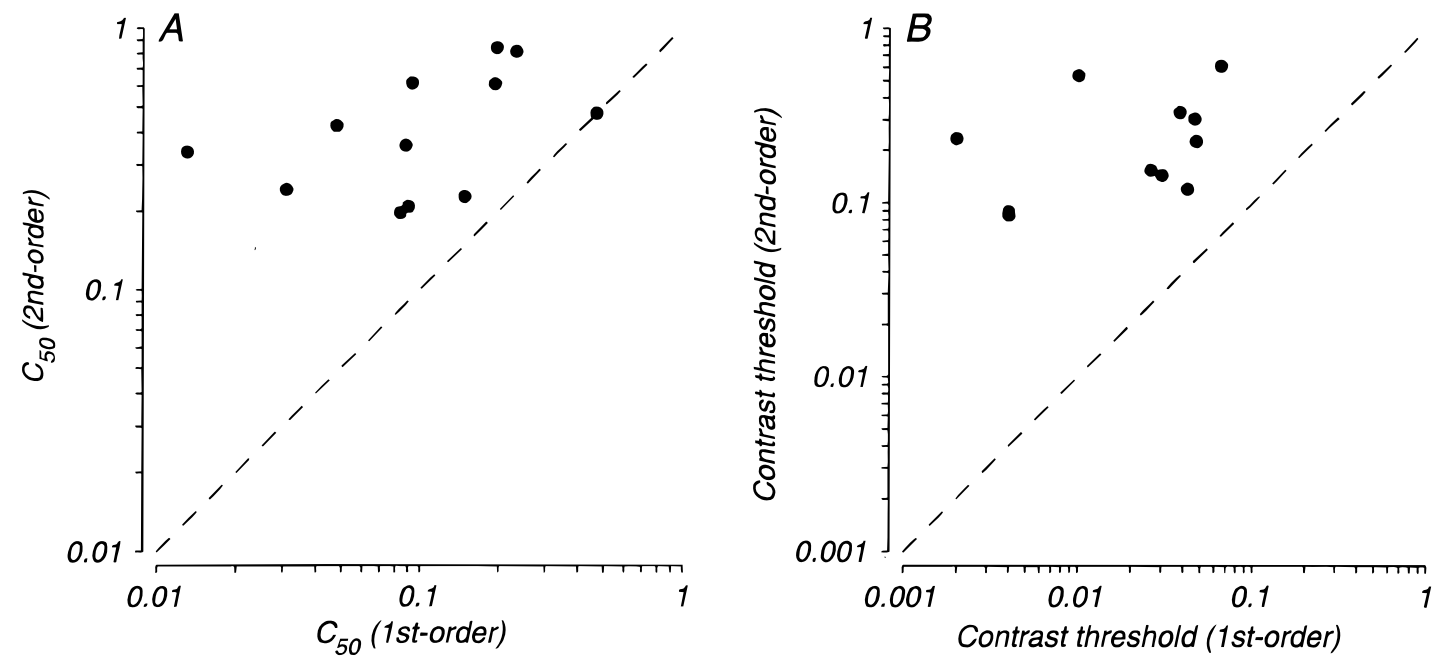

Fig. 9. Comparison of contrast response for first-order and second-order gratings for the MT neurons that were selective for both firstand second-order motion. A: $\mathrm{C}_{50}$ (contrast evoking half-peak response). B: Contrast threshold. Other conventions are as in Fig. 8.

of the carrier and the envelope are sufficiently different, the motion of this stimulus is second order, i.e. there is no luminance component that falls within the neuron's spatio-temporal tuning pass band (see Fig. 1 in Zhou \& Baker, 1994). We wondered if MT neurons would respond in a similar manner to different kinds of second-order motion and therefore measured the responses of 30 neurons to envelope stimuli. We fixed the spatial frequency of the (drifting) modulator at the neuron's preferred spatial frequency and systematically varied the spatial frequency of the (stationary) carrier over a 4-octave range (of higher spatial frequencies). Fig. 10 shows the results of the envelope (filled and open squares) spatialfrequency tuning experiments for four MT cells. Fig. 10 also shows each neuron's spatial-frequency tuning for conventional sinusoidal gratings for comparison with the envelope data. Fig. 10A shows an example (the only one we found) in which the neuron exhibited a direction-selective response when the carrier frequency of the envelope stimulus exceeded the high-frequency cutoff for first-order gratings. This cell was also responsive and direction-selective for our standard second-order motion stimulus. The data in Fig. 10B show non-direction-selective envelope responses over a range of carrier frequencies up to and exceeding the neuron's high-frequency cutoff for first-order gratings. This cell was not direction selective, but was orientation selective for both first- and second-order gratings. The responses to envelope stimuli containing high-frequency carriers, like those illustrated in Figs. 10A and 10B appeared to be genuine responses to second-order motion. Most of the remaining neurons did not respond to envelope stimuli containing highfrequency carriers, and thus did not respond to second-order motion. Many responded like those illustrated in Figs. 10C and 10D, when the carrier and modulator frequencies were within a factor of 1-4 of each other, and within the cell's spatial pass band. In many cases (e.g. Fig. 10D), MT neurons responded to envelope stimuli in the same way a motion energy detector would, reversing preferred direction when the carrier frequency was a factor of 2 higher than the modulator frequency (Adelson \& Bergen, 1985).

\section{Discussion}

In our experiments, almost all MT neurons responded vigorously and selectively to first-order motion. Only a small subset of these neurons showed significant selectivity for second-order motion, and few cells responded as well to second-order motion as they did to first-order motion. The same pattern of results holds for our small sample of V1 neurons. Nonetheless, a minority of our MT (25\%) and V1 (9\%) cells showed significant selectivity for both first- and second-order motion. In MT, those cells tended to have slightly broader spatial tuning and better contrast sensitivity for first-order motion than other cells, but their properties did not otherwise differ from the remainder of our sample. These neurons tended to prefer roughly similar directions and spatial frequencies for first- and second-order motion, and preferred lower temporal frequencies for second-order motion. Though the responses of these cells to high-contrast first- and second-order gratings were correlated, their contrast sensitivity was much poorer for second-order gratings.

\section{Comparison with previous results}

We are aware of only a single previous report of MT responses to second-order motion. In that study, Albright (1992) found that most MT neurons $(87 \%$ ) were selective for the direction of secondorder motion. This is a much larger fraction than we found $(25 \%)$. This is an important difference, because it leads us to adopt a rather different view than Albright about the role of MT in processing visual motion. The difference between these results might be due in part to methodology. We recorded in anesthetized monkeys, while Albright recorded in alert monkeys. While most evidence suggests that MT properties are similar in alert and anesthetized animals, it is conceivable that anesthesia might have a selective effect on responses to second-order motion. We have recently compared neuronal responses recorded in anesthetized monkeys to those recorded in an alert monkey using the same stimuli (O'Keefe \& Movshon, 1996). In our hands, neuronal responses to secondorder motion in the alert monkey were (on average) more vigorous, but no more selective than those in anesthetized monkeys.

Another difference is that we used somewhat different kinds of first- and second-order motion stimuli than Albright. Albright used a flicker-defined bar that drifted over a static texture for his secondorder stimulus, while we used a rather similar flicker-defined squarewave grating that drifted over a static texture. The first-order motion 


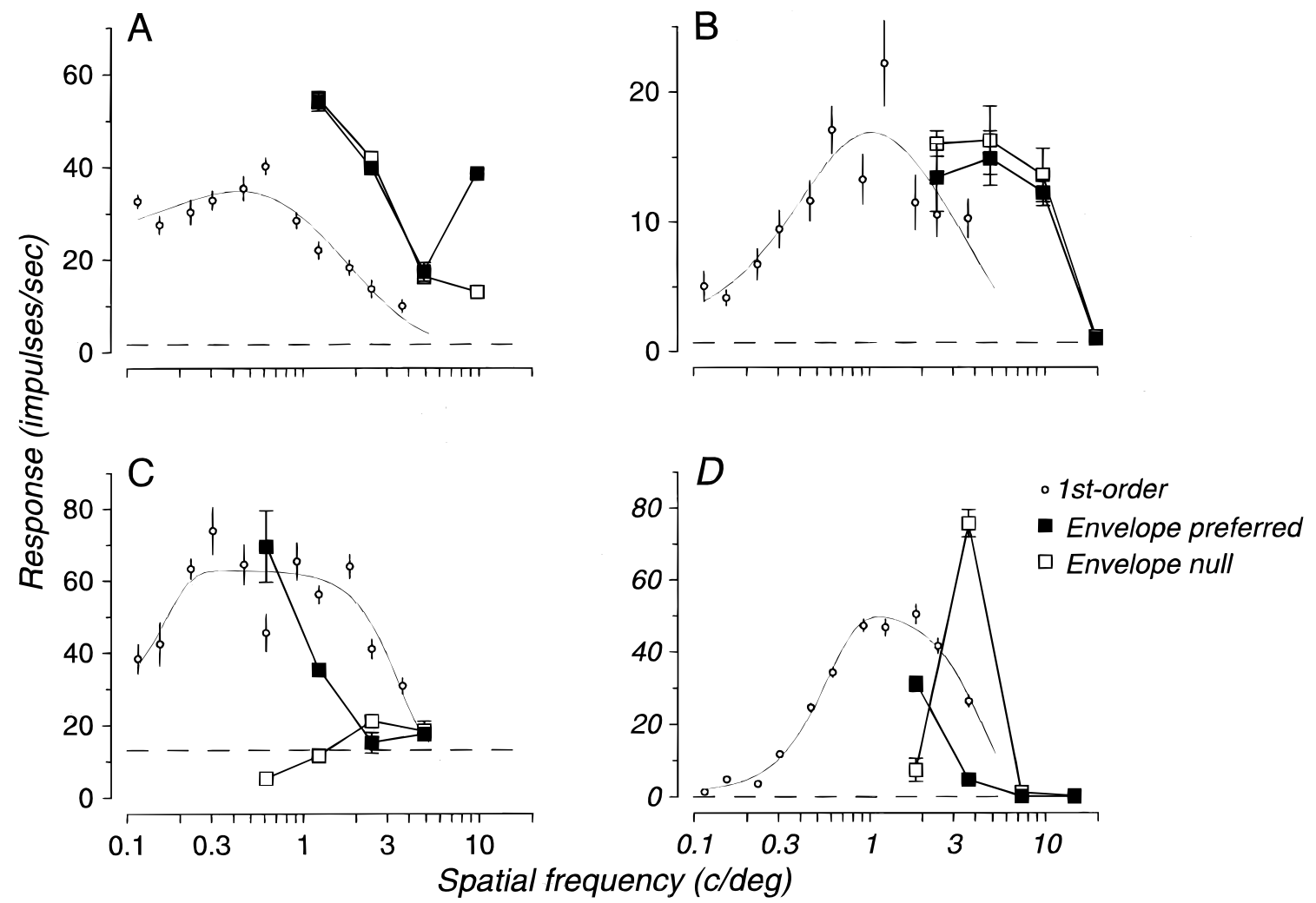

Fig. 10. Responses of four MT neurons to drifting second-order envelope stimuli. Response is plotted as a function of the carrier spatial frequency. Filled squares represent preferred direction responses for envelope stimuli, open squares represent null direction responses for envelope stimuli. Open circles represent spatial-frequency tuning for first-order gratings drifting in the preferred direction. Error bars are \pm 1 standard error of the mean. A: Envelope frequency (the spatial frequency of the drifting modulator) $0.61 \mathrm{cycle} / \mathrm{deg}$. B: Envelope frequency 1.22 cycles/deg. C: Envelope frequency 0.31 cycle/deg. D: Envelope frequency $1.84 \mathrm{cycles} / \mathrm{deg}$.

stimuli were different-Albright used a luminous bar that drifted over a static texture, while we used a drifting sinusoidal grating without static texture. It seems unlikely that Albright's secondorder stimulus was more effective than ours, but possible that Albright's first-order stimulus was less effective than ours, because the textured background can reduce the response and/or direction selectivity of MT neurons (Olavarria et al., 1992; O'Keefe \& Movshon, 1996). A combination of these factors might account for the difference between Albright's results and our own.

A final issue of potential importance is sampling. There is no reason to suppose that experiments in alert monkeys record from the same population of neurons as experiments in anesthetized animals, and it may be that Albright's strategy for sampling units or the properties of his microelectrodes somehow enriched his population in neurons responsive to second-order motion. This possibility is attractive because our findings on the properties of neurons that did respond to second-order motion are similar to Albright's: (1) most, but not all, of the neurons that were selective for second-order motion preferred similar directions for first- and second-order motion (Fig. 7); (2) neurons were significantly less direction selective; and (3) significantly less responsive for secondorder motion than they were for first-order motion.

\section{Are MT cells form-cue invariant?}

Based in part on his experiments with second-order motion, Albright has proposed that MT neurons respond to a wide variety of moving stimuli regardless of the cue that conveys the motion. This "form-cue invariance" would have the advantageous property of providing sensitivity to motion independent of the visual features that define the moving object (Albright, 1992, 1993). However, both our results and those of others suggest that most MT neurons fall far short of the idealized form-cue invariance postulated by Albright. Part of this shortfall is evident in the weak response (Fig. 3) and poor selectivity (Fig. 4) that MT neurons show to high-contrast second-order stimuli. Perhaps more important is that even neurons responding vigorously to high-contrast second-order motion had very poor contrast sensitivity for this motion-no MT neurons responded to moderate contrasts $(\sim 0.1)$ at which secondorder motion is clearly visible to human observers. Another failure of form-cue invariance is evident from earlier work from our laboratory showing that most MT neurons respond poorly to stimuli in which motion information is carried by chromatic rather than luminance cues (Gegenfurtner et al., 1994), although Dobkins and Albright (1994) have shown that chromatic information can unconfound ambiguous motion stimuli for MT neurons. Also, Olavarria et al. (1992) compared the responses of MT neurons to bar stimuli and backgrounds defined by uniform luminance or by texture. They found that the response and/or the direction selectivity of many MT neurons varied with the cues (uniform luminance $v s$. texture) used to define the stimuli, even when all of the cues were first order.

It must, however, be recalled that we did find a few MT cells whose response was similar for first- and second-order motion 
(Figs. 2A and 2B) just as Gegenfurtner et al. (1994) found some MT cells that responded well to chromatic targets. Thus, a subpopulation of MT neurons may be, in a broad sense, form-cue invariant, even if this property represents the exception rather than the rule.

\section{Properties of cells sensitive to second-order motion}

Previous studies have revealed that some functional segregation within MT may be revealed by the use of moving two-dimensional patterns. Adelson and Movshon (1982) proposed that the perceived direction of plaids (the sum of two drifting sinusoids) was derived from an "intersection of constraints" defined by the velocity vectors of the components, and Movshon et al. (1985) showed that some MT neurons (pattern-direction selective) were capable of signaling the direction of these patterns in a manner consistent with the percept. Patterns composed of the sum of two sinusoids (including plaids) contain detectable second-order motion signals (Badcock \& Derrington, 1985, 1989; Derrington \& Badcock, 1985; Derrington et al., 1992) that can bias (Ferrera \& Wilson, 1990; Yo \& Wilson, 1992) or even reverse (Derrington et al., 1992) the perceived pattern direction compared to that predicted by an intersection of constraints model. Wilson and colleagues (Wilson et al., 1992; Wilson, 1994; Wilson \& Kim, 1994) proposed a model to account for the perceived direction of plaid patterns by combining first-order and second-order motion signals. In the most recent incarnation of the model (Wilson, 1994; Wilson \& Kim, 1994), the output is from pattern-direction selective neurons in area MT that receive input from both first-order and second-order component-direction selective MT neurons. Thus, the model predicts that MT pattern-direction selective neurons should respond to both first- and second-order motion, while separate populations of MT component-direction selective neurons should respond to firstorder motion and second-order motion. Our data do not support this prediction: we found no differences in the proportion of component- and pattern-direction selective cells that were selective for second-order motion. While we did find that cells sensitive to second-order motion were somewhat more sensitive to contrast and less selective for spatial frequency than other neurons, there is no other evidence that the cells showing significant selectivity for second-order motion formed a distinct subpopulation within MT.

\section{Are different second-order motion stimuli processed by the same mechanisms?}

We measured responses of a subset of our neurons to two kinds of second-order motion stimuli-microbalanced flicker stimuli (Chubb \& Sperling, 1988, 1989) and drifting "envelope" stimuli (Albrecht \& De Valois, 1981; Zhou \& Baker, 1993, 1994). Most MT neurons did not respond selectively to either envelope or microbalanced second-order motion stimuli, but the few envelope-responsive cells we did find also responded to microbalanced second-order motion. Only three of 30 cells tested exhibited bandpass spatial-frequency tuning for the carrier like that illustrated by Zhou and Baker (1993, 1994) for cat area 17 and 18 neurons. Thus on the basis of this limited test, there is no evidence that different subpopulations of MT cells process different kinds of second-order signal.

\section{Conclusion}

Our results raise as many questions as they answer. On the one hand, we feel secure in asserting that MT does not appear to function as a homogeneous "cue-invariant" motion analyzing system, which processes information about all kinds of motion. Not only do second-order stimuli fail to elicit reliable direction-selective responses from most MT cells, but we have previously shown that chromatically modulated targets similarly fail to elicit a vigorous selective response in these cells (Gegenfurtner et al., 1994). But to establish what MT, globally, does not do, does not answer the question of where and how second-order motion signals are processed. One possibility is that the small population of MT cells that is responsive to second-order motion does in fact convey a behaviorally relevant signal. This seems unlikely, given the neurons' poor contrast sensitivity for second-order targets, but cannot definitively be ruled out. An alternative is that there exist neurons in another area of the macaque's visual cortex that are better adapted to the task of processing second-order motion signals. In support of this view, Greenlee and Smith (1997) have recently reported in human patients that the distributions of brain damage associated with deficits in first- and second-order motion perception are somewhat different. To decide between these possibilities will require combining physiological and behavioral measurements, and we are presently conducting suitable experiments in awake, behaving monkeys.

\section{Acknowledgments}

This work was supported by grants from the National Eye Institute (F32 EY06371 to L.P.O. and EY02017 to J.A.M.) and by the Howard Hughes Medical Institute. Karl Gegenfurtner wrote the display software libraries. Jack Beusmans, Matteo Carandini, and Peter Hyde helped in some of the experiments.

\section{References}

Adelson, E.H. \& Bergen, J. (1985). Spatio-temporal energy models for the perception of motion. Journal of the Optical Society of America A 2, 284-299.

Adelson, E.H. \& Movshon, J.A. (1982). Phenomenal coherence of moving visual patterns. Nature 300, 523-525.

Albrecht, D.G. \& De Valois, R.L. (1981). Striate cortex responses to periodic patterns with and without the fundamental harmonics. Journal of Physiology 319, 497-514.

Albrecht, D.G. \& Hamilton, D.B. (1982). Striate cortex of monkey and cat: Contrast response function. Journal of Neurophysiology 48, 217237.

AlbRight, T.D. (1992). Form-cue invariant motion processing in primate visual cortex. Science 255, 1141-1143.

Albright, T.D. (1993). Cortical processing of visual motion. Reviews of Oculomotor Research 5, 177-201.

BADCock, D.R. \& Derrington, A.M. (1985). Detecting the displacement of periodic patterns. Vision Research 25, 1253-1258.

Badcock, D.R. \& Derrington, A.M. (1989). Detecting the displacements of spatial beats: No role for distortion products. Vision Research 29, 731-739.

Britten, K.H., Newsome, W.T., Shadlen, M.N., Celebrini, S. \& MovSHON, J.A. (1996). A relationship between behavioral choice and the visual responses of neurons in macaque MT. Visual Neuroscience 13, 87-100.

Britten, K.H., Shadlen, M.N., Newsome, W.T., \& Movshon, J.A. (1992). The analysis of visual motion: A comparison of neuronal and psychophysical performance. Journal of Neuroscience 12, 4745-4765.

Britten, K.H., Shadlen, M.N., Newsome, W.T. \& Movshon, J.A. (1993). Responses of neurons in macaque MT to stochastic motion signals. Visual Neuroscience 10, 1157-1169.

Cavanagh, P. \& Mather, G. (1989). Motion: The long and short of it. Spatial Vision 4, 103-129.

Chubb, C. \& Sperling, G. (1988). Drift-balanced random stimuli: A general basis for studying non-Fourier motion perception. Journal of the Optical Society of America A 5, 1986-2007.

Chubb, C. \& Sperling, G. (1989). Two motion perception mechanisms 
revealed through distance-driven reversal of apparent motion. Proceedings of the National Academy of Sciences of the U.S.A. 86, 2985-2989.

DeAngelis, G.C., Ohzawa, I. \& Freeman, R.D. (1993a). Spatiotemporal organization of simple-cell receptive fields in the cat's striate cortex. I. General characteristics and postnatal development. Journal of Neurophysiology 69, 1091-1117.

DeAngelis, G.C., Ohzawa, I. \& Freeman, R.D. (1993b). Spatiotemporal organization of simple-cell receptive fields in the cat's striate cortex. II. Linearity of temporal and spatial summation. Journal of Neurophysiology 69, 1118-1135.

Derrington, A.M. \& Badcock, D.R. (1985). Separate detectors for simple and complex grating patterns? Vision Research 25, 1869-1878.

Derrington, A.M., Badcock, D.R. \& Holroyd, S.A. (1992). Analysis of the motion of 2-dimensional patterns: Evidence for a second-order process. Vision Research 32, 699-707.

DobKIns, K.R. \& ALbright, T.D. (1994). What happens if it changes color when it moves?: The nature of chromatic input to macaque visual area MT. Journal of Neuroscience 14, 4854-4870.

Emerson, R.C., Bergen, J.R. \& Adelson, E.H. (1992). Directionally selective complex cells and the computation of motion energy in cat visual cortex. Vision Research 32, 203-218.

Felleman, D.J. \& Van Essen, D.C. (1991). Distributed hierarchical processing in the primate cerebral cortex. Cerebral Cortex 1, 1-47.

Felleman, D.J. \& KaAs, J.H. (1984). Receptive field properties of neurons in middle temporal visual area (MT) of owl monkeys. Journal of Neurophysiology 52, 488-513.

Ferrera, V.P. \& Wilson, H.R. (1990). Perceived direction of moving two-dimensional patterns. Vision Research 30, 273-287.

FleEt, D.J. \& LANGLEY, K. (1994). Computational analysis of non-Fourier motion. Vision Research 34, 3057-3079.

Gegenfurtner, K.R., Kiper, D.C., Beusmans, J.M., Carandini, M., ZAIDI, Q. \& Movshon, J.A. (1994). Chromatic properties of neurons in macaque MT. Visual Neuroscience 11, 455-466.

Greenlee, M.W. \& Smith, A.T. (1997). Detection and discrimination of first- and second-order motion in patients with unilateral brain damage. Journal of Neuroscience 17, 804-818.

Leventhal, A.G., Thompson, K.G., Liu, D., Zhou, Y. \& Ault, S.J. (1995). Concomitant sensitivity to orientation, direction, and color of cells in layers 2, 3, and 4 of monkey striate cortex. Journal of Neuroscience 15, 1808-1818.

Levick, W.R. \& Thibos, L.N. (1982). Analysis of orientation bias in cat retina. Journal of Physiology 329, 243-261.

LevitT, J.B., Kiper, D.C. \& Movshon, J.A. (1994). Receptive fields and functional architecture of macaque V2. Journal of Neurophysiology 71, 2517-2542.

Lu, Z.L. \& Sperling, G. (1995). The functional architecture of human visual motion perception. Vision Research 35, 2697-2722.

Maunsell, J.H.R. \& Newsome, W.T. (1987). Visual processing in monkey extrastriate cortex. Annual Review of Neuroscience 10, 363-401.

Mclean, J. \& Palmer, L.A. (1989). Contribution of linear spatiotemporal receptive field structure to velocity selectivity of simple cells in area 17 of cat. Vision Research 29, 675-679.

Mclean, J., RaAb, S. \& Palmer, L.A. (1994). Contribution of linear mechanisms to the specification of local motion by simple cells in areas 17 and 18 of the cat. Visual Neuroscience 11, 271-294.

Merrill, E.G. \& Ainsworth, A. (1972). Glass-coated platinum-plated microelectrodes. Medical and Biological Engineering 10, 662-671.

Movshon, J.A., Adelson, E.H., GizzI, M.S. \& Newsome, W.T. (1985). The analysis of moving patterns. In Pattern Recognition Mechanisms, ed. Chagas, C., Gattass, R. \& Gross, C., pp. 117-151. Vatican City: Vatican Press.

Movshon, J.A. \& Newsome, W.T. (1996). Visual response properties of striate cortical neurons projecting to area MT in macaque monkeys. Journal of Neuroscience 16, 7733-7741.

Movshon, J.A., Thompson, I.D. \& Tolhurst, D.J. (1978). Spatial summation in the receptive fields of simple cells in the cat's striate cortex. Journal of Physiology 283, 53-77.

Newsome, W.T., Britten, K.H. \& Movshon, J.A. (1989). Neuronal correlates of a perceptual decision. Nature 341, 52-54.

Newsome, W.T. \& PARE, E.B. (1988). A selective impairment of motion perception following lesions of the middle temporal visual area (MT). Journal of Neuroscience 8, 2201-2211.
O’Keefe, L.P. \& Movshon, J.A. (1996). First- and second-order motion processing in superior temporal sulcus neurons of the alert macaque. Society for Neuroscience Abstracts 22, 716.

Olavarria, J.F., DeYoe, E.A., Knierim, J.J., Fox, J.M. \& Van Essen, D.C. (1992). Neural responses to visual texture patterns in middle temporal area of the macaque monkey. Journal of Neurophysiology $\mathbf{6 8}$, $164-181$.

QIAN, N. \& ANDERSEN, R.A. (1994). Transparent motion perception as detection of unbalanced motion signals. II. Physiology. Journal of Neuroscience 14, 7367-7380.

Qian, N., Andersen, R.A. \& Adelson, E.H. (1994). Transparent motion perception as detection of unbalanced motion signals. III. Modeling. Journal of Neuroscience 14, 7381-7392.

ReID, R.C., SoOdAK, R.E. \& Shapley, R.M. (1987). Linear mechanisms of directional selectivity in simple cells of cat striate cortex. Proceedings of the National Academy of Sciences of the U.S.A. 84, 40-44.

Salzman, C.D., Britten, K.H. \& Newsome, W.T. (1990). Cortical microstimulation influences perceptual judgements of motion direction. Nature 346, 174-177.

Salzman, C.D., Murasugi, C.M., Britten, K.H. \& Newsome, W.T. (1992). Microstimulation in visual area MT: Effects on direction discrimination performance. Journal of Neuroscience 12, 2331-2355.

Salzman, C.D. \& Newsome, W.T. (1994). Neural mechanisms for forming a perceptual decision. Science 264, 231-237.

Shadlen, M.N., Britten, K.H., Newsome, W.T. \& Movshon, J.A. (1996). A computational analysis of the relationship between neuronal and behavioral responses to visual motion. Journal of Neuroscience 16, 1486-1510.

Simoncelli, E.P., Bair, W.D., Cavanaugh, J.R. \& Movshon, J.A. (1996). Testing and refining a computational model of neural responses in area MT. Investigative Ophthalmology and Visual Science 37, S916.

Sperling, G. (1989). Three stages and two systems of visual processing. Spatial Vision 4, 183-207.

VAN Essen, D.C. (1985). Functional organization of the primate visual cortex. In Cerebral Cortex, Volume 3, ed. Jones, E.G. \& Peters, A., pp. 259-330. New York: Plenum.

VAn Essen, D.C. \& Maunsell, J.H.R. (1983). Hierarchical organization and functional streams in the visual cortex. Trends in Neuroscience 6, $370-375$.

VAn SAnten, J.P.H. \& Sperling, G. (1984). Temporal covariance model of human motion perception. Journal of the Optical Society of America A 1, 451-473.

Van Santen, J.P.H. \& Sperling, G. (1985). Elaborated Reichardt detectors. Journal of the Optical Society of America A 2, 300-321.

Victor, J.D. \& ConTe, M.M. (1992). Evoked potential and psychophysical analysis of Fourier and non-Fourier motion mechanisms. Visual Neuroscience 9, 105-123.

Watson, A.B. \& Ahumada, A.J. (1983). A look at motion in the frequency domain. In Motion: Representation and Perception, ed. Tsotsos, J.K., pp. 1-10. New York: Association for Computing Machinery.

Watson, A.B. \& AhumadA, A.J. (1985). Model of human visual motion sensing. Journal of the Optical Society of America A 2, 322-342.

WILson, H.R. (1994). The role of second-order motion signals in coherence and transparency. In Higher-Order Processing in the Visual System, ed. Bock, G.R. \& Goode, J.A., pp. 269-271. London: Ciba Foundation.

Wilson, H.R., Ferrera, V.P. \& Yo, C. (1992). A psychophysically motivated model for two-dimensional motion perception. Visual Neuroscience 9, 79-97.

Wilson, H.R. \& KIM, J. (1994). A model for motion coherence and transparency. Visual Neuroscience 11, 1205-1220.

Yo, C. \& Wilson, H.R. (1992). Perceived direction of moving twodimensional patterns depends on duration, contrast and eccentricity. Vision Research 32, 135-147.

ZANKER, J.M. \& HuPGENS, I.S. (1994). Interaction between primary and secondary mechanisms in human motion perception. Vision Research 34, 1255-1266.

ZHou, Y.X. \& BAKer, C.L., JR. (1993). A processing stream in mammalian visual cortex neurons for non-Fourier responses. Science 261, 98-101.

ZHOU, Y.X. \& BAKER, C.L., JR. (1994). Envelope-responsive neurons in areas 17 and 18 of cat. Journal of Neurophysiology 72, 2134-2150. 